\title{
André Taïeb, Chants séfarades des synagogues du Languedoc
}

Atlas sonore en Languedoc-Roussillon, 2003

Hervé Roten

\section{OpenEdition}

\section{Journals}

Édition électronique

URL : http://journals.openedition.org/ethnomusicologie/545

ISSN : 2235-7688

Éditeur

ADEM - Ateliers d'ethnomusicologie

Édition imprimée

Date de publication : 1 janvier 2004

Pagination : $377-378$

ISBN : 2-8257-0910-7

ISSN : $1662-372 X$

Référence électronique

Hervé Roten, "André Taïeb, Chants séfarades des synagogues du Languedoc », Cahiers

d'ethnomusicologie [En ligne], 17 | 2004, mis en ligne le 13 janvier 2012, consulté le 20 avril 2019. URL : http://journals.openedition.org/ethnomusicologie/545

Ce document a été généré automatiquement le 20 avril 2019.

Tous droits réservés 


\section{André Taïeb, Chants séfarades des synagogues du Languedoc}

Atlas sonore en Languedoc-Roussillon, 2003

Hervé Roten

\section{RÉFÉRENCE}

André Taïeb, Chants séfarades des synagogues du Languedoc, Atlas sonore en LanguedocRoussillon. Réalisation: Pierre-Luc Ben Soussan; texte: Amnon Shiloah. 1 CD CLRMDT 1017, 2003.

1 La communauté juive de France est la troisième du monde après celles des Etats-Unis et d'Israël. Forte d'environ 600000 membres, elle est en réalité particulièrement composite. Originellement établie en Alsace-Lorraine, dans l'ancien Comtat Venaissin ou bien encore dans le Sud-Ouest de la France, avec les soubresauts de l'histoire du XX $\mathrm{XX}^{\mathrm{e}}$ siècle, les migrations et les immenses changements sociodémographiques qui l'ont affectée, la judaïcité française est devenue une illustration vivante d'une extraordinaire diversité culturelle puisant à des racines multiples la pluralité de ses expressions contemporaines.

2 On connaît relativement bien l'histoire des communautés juives de France, leurs particularités linguistiques ou sociologiques. On connaît moins leur patrimoine musical. Aussi faut-il saluer l'initiative du Centre Languedoc-Roussillon des Musiques et Danses Traditionnelles (CLRMDT) d'avoir publié, dans le cadre de la collection « Atlas Sonore en Languedoc-Roussillon», un CD consacré à André Taïeb - Chants séfarades des synagogues du Languedoc. Cet enregistrement salutaire s'appuie sur le remarquable travail de collecte des chants des synagogues de Montpellier et sa région mené par Pierre-Luc Ben Soussan, musicien intervenant à l'association Mosaïque Musiques et fondateur de l'ensemble Naguila avec lequel il a déjà réalisé deux CD consacrés au chantre André Taïeb (Chants mystiques séfarades et Hallel).

3 Le propos du présent disque est toutefois différent: il s'inscrit dans la volonté de valoriser la mémoire musicale des cultures traditionnelles présentes en Languedoc-Roussillon, 
qu'elles soient occitane, catalane, juive, maghrébine, gitane, asiatique... A défaut de pouvoir être enregistré in situ - l'utilisation d'appareils électriques est interdite durant la majeure partie des fêtes juives - ce CD nous offre une vision de la liturgie séfarade assez proche de la réalité. Dans les synagogues de rite nord-africain, la prière est toujours chantée a cappella par le hazzan (chantre) et les fidèles, soit ensemble, soit séparément, sous une forme soit responsoriale, soit antiphonale. André Taïeb présente ici quatorze chants synagogaux de rite constantinois, qu'il interprète a cappella.

André Taïeb est né en 1931 à Constantine, haut lieu de la production musicale algérienne illustré notamment par Cheikh Raymond, un des maîtres du ma'louf (genre issu de la nouba, alternant des pièces vocales et instrumentales). Très jeune, il a été formé à l'art du mawwal (improvisation vocale a cappella sur un mode musical) et du ma'louf. En 1962, il quitte l'Algérie et s'installe à Belfort où il devient chantre de la synagogue. En 1988, il se retire à Montpellier où il officie à la synagogue Mazel Tov.

5 André Taïeb est incontestablement un des maîtres de la hazzanout (art cantorial) constantinoise, une tradition qui remonte à l'Espagne médiévale, alors que les Juifs séfarades vivaient en bonne intelligence avec leurs voisins musulmans ou chrétiens. Entre le $\mathrm{X}^{\mathrm{e}}$ et le $\mathrm{XV}^{\mathrm{e}}$ siècle, l'Espagne a été le plus grand centre de

production de la poésie religieuse hébraïque; des milliers de piyyoutim (poèmes liturgiques) ont fleuri au contact des formes variées de la poésie arabe. Ces piyyoutim sont devenus progressivement partie intégrante de la liturgie traditionnelle juive. Lorsque les Séfarades ont été chassés d'Espagne en 1492, une partie importante d'entre eux a trouvé refuge sur le pourtour méditerranéen, notamment en Afrique du Nord. Dans la seconde moitié du XVI ${ }^{e}$ siècle, de puissants courants mystiques ont favorisé la création et la propagation d'une multitude de poésies en hébreu ou en araméen, basées sur des chants populaires turcs, arabes, espagnols ou encore provençaux. Tout fidèle pouvait ainsi utiliser la mélodie de son choix du moment qu'il l'investissait d'une intention spirituelle. Cette conception, notamment véhiculée par l'école kabbalistique de Safed (Palestine), allait favoriser l'introduction des modes arabes (maqamat) dans le chant synagogal oriental, et même parfois remplacer le système des accents bibliques (teamim) traditionnellement appliqué à la lecture de la Torah.

6 A l'exception de quelques cantillations et psalmodies, les mélodies de ce disque relèvent incontestablement de la systématique musicale arabe. La voix est nasalisée, les mélismes nombreux, l'improvisation et le développement modal obéissent aux règles subtiles impliquées par le maqam. Le deuxième morceau, «Lakhem yegi'ei ha-zeman» offre un bel exemple d'ornementation et de développement modal. La voix s'élance dans une multitude d'arabesques avant de redescendre à chaque fin de phrase. Les troisième, quatrième et douzième mélodies possèdent des caractéristiques musicales très proches de celles des communautés de rite portugais (modes et formules mélodiques plus ou moins similaires); seule l'ornementation, beaucoup plus abondante, varie. Les cantillations bibliques (plages 5, 11 et 13), tout en sobriété et en intériorité, sont magnifiquement interprétées par André Taïeb.

7 Quelques bémols toutefois sont à signaler. La voix du chantre présente de temps à autre de légers signes de fatigue vocale. Plus ennuyeux, le sous-titre du $C D$, «Chants séfarades des synagogues du Languedoc», laisse à penser que la tradition constantinoise, représentée par André Taïeb, est chantée dans toutes les synagogues séfarades de la région... ce qui est loin d'être le cas. Aujourd'hui, les musiques synagogales varient selon l'origine des fidèles, du hazzan, voire du rabbin; et il n'est pas rare que des airs de 
différentes traditions soient chantés dans un même lieu de culte. Dans une publication à visée ethnologique, on aurait souhaité avoir une idée plus précise de la représentativité des airs de ce disque par rapport à l'ensemble des traditions musicales juives languedociennes. Dernière remarque: la notice rédigée par Amnon Shiloah, spécialiste incontesté des musiques juives et arabes, explique fort bien les principales caractéristiques de la liturgie musicale juive (définition du piyyout, des te'amim, etc.), mais sans développer les particularités stylistiques de la hazzanout constantinoise, qui est pourtant au cœur de ce disque.

8 Ces quelques critiques n'affectent en rien la qualité et l'intérêt de cette publication, qui trouvera sa place dans toute bonne discothèque. 